\title{
Chapter 1 \\ Education in Crisis. Transforming Schools for a Post-Covid-19 Renaissance
}

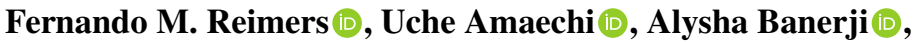 \\ and Margaret Wang $(D)$
}

\subsection{An Education Crisis like No Other}

The Covid-19 pandemic shocked education systems around the world in ways for which they were not prepared. The combination of the health and economic shocks to students and their families, and of the constraints to in person instruction resulting from the social distancing measures, limited the opportunities of many students to learn. While educators and education leaders attempted to create alternative forms of remote education, those were improvised and poorly supported. As a result, students not only failed to learn what new material was expected of them in the curriculum, but also lost existing knowledge, skills and motivation, as a result of their deficient engagement with school. Although published studies of the impact of the pandemic on educational opportunity are limited at this point, those available indicate that there will be considerable learning loss, more so for disadvantaged students and in the global south (Reimers, 2021a, 2022).

A recent review of research on learning loss during the pandemic was able to identify only eight published studies, all focusing on OECD countries which experienced relatively short periods of school closures (Belgium, the Netherlands, Switzerland, Spain, the United States, Australia, and Germany). These studies confirm learning

\footnotetext{
F. M. Reimers $(\varangle) \cdot$ U. Amaechi

Harvard Graduate School of Education, 13 Appian Way, Gutman 461, Cambridge, MA 02138, USA

e-mail: Fernando_Reimers@harvard.edu

U. Amaechi

e-mail: uche_amaechi@gse.harvard.edu
}

\author{
A. Banerji \\ Harvard Graduate School of Education, 65 Hancock Street, Apt 2R, Boston, MA 02114, USA \\ e-mail: alysha_banerji@g.harvard.edu \\ M. Wang \\ Harvard Graduate School of Education, 2 Corte Trovata, Irvine, CA 92606, USA
}


loss in most cases and, in some, increases in educational inequality. Not all educational subjects or cohorts of students were affected equally, however; the same documents report heterogeneous effects of closures on learning for various school subjects and education levels (Donnelly \& Patrinos, 2021).

A recent study of the educational strategies during the pandemic in thirteen different countries concludes that the educational impact of the pandemic was mediated by social class and country of residence:

\footnotetext{
The pandemic created a context in which students in least developed countries experienced the brunt of six mutually reinforcing challenges: the longest school closures, the lowest levels of resources and institutional capacity to mitigate learning loss, lower levels of access to vaccines, the greatest increases in poverty, lower effectiveness of alternative modalities to education, and the greatest levels of social and educational inequality. For these varied reasons, it is likely that the two most important mediators of the COVID-19 pandemic's impact on educational opportunity were nationality and social class. (Reimers, 2022, 463).
}

As a result of this disproportionate educational impact on the pandemic in the Global South, existing educational disparities with the Global North widened. Students lost much of what they had learned the previous year, many disengaged from school altogether, and dropout rates increased. The result was education development in reverse, at full speed. Teachers and education leaders watched decades of educational progress vanish in a couple of years. Furthermore, as the pandemic continues to ravage educational opportunity in the jurisdictions in which in person instruction has not resumed, there is growing concern over what will likely be considered the most serious education crisis in the history of public education-and its ripple effects in expanding poverty, social inequality and other social challenges.

The response to this crisis must include not only immediate recovery efforts, directed towards mitigating learning loss and disparities in educational access, but also new motions to address the previous deficiencies of education systems-deficiencies which the COVID-19 pandemic has brought to the fore. Especially in the Global South, the pandemic hit education systems already experiencing a "learning crisis," the result of low quality and relevancy of instruction for many children around the world (World Bank, 2018).

This urgency to "build back better" has placed the subject of curriculum reform squarely on the education policy agenda of most education systems. In addition to addressing gaps in existing systems and unmet past needs, COVID-19 recovery is therefore an opportunity for reform - new efforts, which reframe the goals of the past considering the needs revealed or created by the pandemic and ensure that schools do a better job in preparing students to build a more inclusive and sustainable world (Reimers, 2021a).

Even before the pandemic, educational systems and institutions around the world had begun to direct their attention to the subject of what it is, precisely, that students should learn in a rapidly changing world. In September 2019, UNESCO established an International Commission on the Futures of Education to develop a report to animate broad global dialogue on the goals of education. The report, published in November of 2021, underscored the urgency of enhancing the relevance of education by helping students develop a broad range of competencies, cognitive as well 
as socio-emotional and focused with greater intensity than two previous reports on the future of education published by UNESCO in 1972 and 1996 on the urgency to rethink pedagogy, curriculum, the teaching profession and the role and organization of schools (UNESCO, 2021). Other efforts similarly focused on revamping the focus of curriculum, such as the OECD's Future of Education and Skills 2030 Initiative, as well as a diversity of national efforts (OECD, 2021). For example, a review of education plans in 15 low-income countries in Africa and Asia conducted by the Global Education Partnership, found that all of them prioritized twenty-first century skills (Global Partnership for Education, 2020, vi). Other studies of recent curriculum reforms confirm this growing interest in broadening the aims of the curriculum (Reimers, 2020a).

The COVID-19 pandemic has accelerated the movement towards reframing educational goals in several ways. First, the new social and economic challenges created or aggravated by the pandemic_-including job displacement, gender and social inequality, social fragmentation, democratic governance, and climate change-call for greater intentionality on the part of educational institutions to equip students with the skills to address these challenges. Second, the learning loss and increased rates of school dropout caused by the pandemic will require greater focus into the future, in helping the affected generation develop competencies to catch up, develop the skills necessary to participate in society, and address those larger sociopolitical challenges. Third, the arrangements for educational continuity created during the pandemic, and the needs surfaced by the crisis, brought into focus the importance of prioritizing relevant competencies and to align these learning goals with existing levels of capacity. The period of learning remotely made evident that some students were more ready to learn autonomously and online than others and underscored the importance of supporting students in the socio-emotional domains.

The pandemic heightened awareness of the likely impact of global shocks in our lives, and of the need to prepare for them. This interest in the goals of schools will likely continue during the pandemic and beyond as part of the efforts to "build back better."

As education authorities sought to create alternative ways to educate during and after the pandemic, given the constraints on doing so in-person in schools, it became evident that many students, and teachers, lacked the skills to effectively learn independently and online, in addition, many also lacked access to connectivity and devices to learning online. The great value of reading comprehension as a foundational skill was identified as a major leverage point, as students had to spend more time reading independently at home. The same was true for organizational skills, the ability to concentrate, and perseverance. The crisis also highlighted the need to address mental health needs and food insecurity for some students and made evident the importance of social interaction to sustain engagement and wellbeing.

Having to deliver education through means that were less capacious than in person instruction caused many educators to reprioritize the curriculum. In some cases, this led to greater attention to providing students emotional and social support, and this in turn underscored the interdependency of cognitive and socio-emotional learning. Reprioritizing the curriculum also led to greater attention to what competencies 
should be the goal of the intended curriculum. As the pandemic laid bare the significance of preexisting challenges, such as poverty, social inequality, or climate change, this added to the urgency of educating students so they could in fact gain the competencies to address these challenges. The questions of how to prepare students for employment, for civic participation, or to contribute to tackling large social challenges such as gender inequality, poverty, social fragmentation, or climate change in a post-pandemic world thus has become critical as the urgency of addressing these challenges has augmented because of the disruptions caused by the pandemic itself.

Paradoxically, this elevated interest in increasing the relevancy of schools-particularly in the Global South, where most students live, and where the impact of the pandemic has been the direst-will have to be addressed in the context of diminished fiscal and institutional capacity, the result of the increased needs caused by the pandemic. This reality underscores the imperative of access to knowledge about how to design implementation strategies that help education systems prepare students with the competencies they need to thrive in a world that is uncertain.

\subsection{A Renewed Interest in the Implementation of Educational Change in the Global South}

The elevated expectations about what schools should teach has created a new need: to discern how to effectively translate goals into practices that successfully transform the culture of education.

This interest in devising effective implementation strategies of more ambitious goals has led to an interest in "what works," in looking for knowledge about how to implement educational change. Where should we draw this knowledge from to meet this need? While there is ample scholarly literature on the topic of educational change and implementation of educational change, much of this knowledge is the product of research on a limited range of countries in the Global North. While valuable, there are some limitations to drawing on the study of implementing educational change in countries with higher levels of fiscal and institutional capacity, especially as the fiscal capacity in most countries in the Global South is further constrained by the pandemic.

While there has been a growing literature on "high performing countries," drawing on cross national comparisons of student knowledge and skills (Lee et al., 2014; Wang, 2013), there are limits to what knowledge about the characteristics and practices of countries where students achieve at high levels can teach us about how to help countries improve, especially if those countries enjoy greater levels of resources and institutionalization of education. After all, there has been very limited improvement even in "high performing countries" in recent decades. Studies of change of levels of student knowledge and skills over two decades - in the forty-nine countries for which data are available since 2000, which include OECD countries and some middle-income countries - show that such learning outcomes increased steadily only 
in Estonia and Portugal. They increased during the latter part of that twenty-year period in Jordan, Macao, Russia, and during the earlier part of that period in Albania, Chile, Colombia, Germany, Israel, Montenegro, Peru, Poland, Qatar and Romania. In a nutshell, most countries did not improve, and only seven OECD member states improved (Chile, Colombia, Estonia, Germany, Israel, Poland and Portugal). Among countries in which much educational research on the process of educational change originates, student performance declined in Australia and did not improve in Canada and the United States (Schleicher, 2019, 11).

Furthermore, the most recent assessment of student knowledge and skills conducted by the OECD, underscores the limitations of existing curricula in preparing students to address issues of considerable significance in an increasingly interdependent world. The latest PISA study reported on students' global knowledge and attitudes towards global topics in four competency domains including the ability to: (1) examine issues of local, global and cultural significance; (2) understand and appreciate the perspectives and worldviews of others; (3) engage in open, appropriate and effective interactions across cultures; and (4) take action for collective well-being. The results of this assessment showed not only low levels of knowledge in these important domains, but considerable disconnects between knowledge and the ability to act on that knowledge to solve problems (Boeren, 2019).

Such limitations of pre-existing studies of high performing systems, limited improvement in OECD countries and low levels of global competency as measured by PISA underscore the necessity to expand the knowledge base on which to base efforts to mitigate and revert the damage caused by the pandemic and to build back better.

Surprisingly, there are considerably fewer studies of recent ambitious efforts of educational change in countries in the Global South than studies in the Global North, even though the former would seem to be most relevant to the task of supporting improvement in the South because of shared institutional and resource constraints. The need for such knowledge stems also from the fact that $90 \%$ of the population of children and youth are educated in the Global South and because the impact of the pandemic will be disproportionate in the Global South. Additionally, efforts to educate students more effectively may need to be based on design and invention, to address the shortcomings of previous efforts as shown by the low levels of global competency revealed by the most recent PISA assessment.

For example, in preparing students to address climate change, evaluations of the effectiveness of existing programs underscore the limitations of approaches that rely exclusively on the transmission of knowledge of the science of climate change (Reimers, 2021b). Rather than import climate change education programs which have not demonstrated success elsewhere, the design of climate change education programs may draw on the best science about how to develop efficacy in other domains, such as civic engagement, so they can support the development of the full range of cognitive, social and emotional competencies that produce climate action efficacy.

The purpose of this book is to contribute to this necessary knowledge base, reviewing the implementation of recent ambitious education reforms in the Global 
South, as well as novel approaches to educate students more effectively for climate action.

Because this renewed emphasis on the education of the whole child via competency-based education and curriculum redesign is likely to be a driver of education efforts in years to come, as education systems seek to rebuild opportunity, and to build back better after the pandemic, there is an urgent need of comparative research on these topics. Learning from countries which have attempted to implement education reform at scale and with the resource constrains more typical of the Global South is likely to be directly relevant to most school systems which will have to operate within similar constraints during and after the pandemic. This book is an effort to address such needs.

\subsection{Focus of This Book}

This book contains seven chapters examining education reforms at the macro, meso, and micro levels. At the macro level, four studies examine national education reforms in Egypt, Senegal, Taiwan, and Vietnam.

Three of these are reforms with an explicit effort to transform the curriculum so students could develop a breadth of cognitive and socio-emotional competencies, these efforts are analogous to those involved in "building back better" to recover educational losses caused by the pandemic. Additionally, Senegal's reform focuses on a reform to scale opportunities for early childhood holistic development integrating education, health, and nutrition. Such cross-sectoral integration is likely to be of great interest soon given increases in poverty, marginalization and food insecurity caused by the pandemic.

At the meso level, a study examines one of the programs that has reached most scale in India in educating for employment while also focusing on the development of breadth of skills. This topic of education for employment has renewed urgency in a recessionary context and one in which automation and artificial intelligence erode existing jobs.

At the micro, or school, level, two of the chapters examine curriculum reforms to help students develop the competencies to adapt to, mitigate and revert climate change. While these two chapters at the micro level focus on the United States, a high-income country, they address the shortcomings of previous approaches to climate change education and suggest how proofs of concept and "niche reforms" can help ambitious curriculum aligned with the goal of adapting, mitigating, and reverting climate change can succeed where others have failed.

These seven studies were conducted as part of a graduate course on comparative education policy analysis taught at the Harvard Graduate School of Education. In this course, students learn about system level reform, curriculum and standards, and teacher preparation. They also learn to compare system level reforms around the world. 
Furthermore, students examine large scale educational change through the integration of five conceptual perspectives: cultural, professional, psychological, institutional and political (Reimers, 2020b). This approach posits that to support large scale implementation of educational change, it is essential to have a complex "theory of mind," which can facilitate communication and collaboration across many stakeholders. That complex theory of mind needs to integrate five alternative ways to construe the process of educational change.

A cultural perspective sees schools as social institutions in interaction with other institutions in society: families, communities, workplaces, religious institutions. The interactions among those institutions and schools mediate the efforts to transform schools. A psychological perspective integrates recent knowledge on how students, teachers and other adults learn a diversity of competencies into the design of curriculum and instruction. A professional perspective attends to how norms, processes, and institutions mobilize expert knowledge to support professional practice-through such measures as teacher professional development or increasing school autonomy, which allows those close to the process of instruction to make the decisions that best serve their students. An institutional perspective focuses on the interactions, coherence, and alignment among the various education processes that support instruction, such as curriculum, professional development, instructional resources, school leadership, and assessment. Finally, a political perspective attends to the negotiation and competition of interests of various stakeholder groups affected by education reform. This framework has been used previously to compare national education reforms (Reimers, 2020a, 2021c).

\subsection{Rationale-Why Study the Implementation of Reforms Which Are Relatively Recent, and Some of Them Still Underway?}

By focusing on the implementation of reforms, these chapters align with literature in the field that emphasizes the importance of the implementation stage of policy reform, as "the crucial stage in the policy cycle in which successes and failures of policies are decided" (Hargrove, 1975 as quoted in Wegrich, 2016). While research on policy implementation has grown in the years since Hargrove described this as the "missing link" in policy studies, the field continues to benefit from the study of how policy goals are translated on the ground, across a range of international contexts. Earlier studies in the field established that the implementation stage was much more than the mechanical adoption, or failure to adopt, of policy intentions, but rather an evolutionary process, in which those involved in policy learned because of turning ideas into programs and actions:

There is no need to feel guilty about failing to carry out a mandate inherent in a policy in a literal way, because literal implementation is literally impossible. Unless a policy matter is narrow and uninteresting (i.e., preprogrammed), the policy will never be able to 
contain its own consequences. Implementation will always be evolutionary; it will inevitably reformulate as well as carry out policy. (Majone \& Wildavsky, 1979, 179-180).

Studying the implementation of ambitious education reforms in the Global South is essential because it advances knowledge about what policies make sense in such contexts. The reason to study reforms in progress is because this helps understand the evolutionary nature of reform. As with previous publications on this topic (Reimers, 2021c), chapters on Vietnam, Egypt, and Taiwan aim at providing careful and detailed descriptions of reforms as they are being carried out.

This study of the implementation of large-scale education reforms highlights the ways in which the process of policy reform is "a learning process...evolutionary and developmental in nature" (Dalin \& Ayono, 1994, xvii). The various chapters in the book show how an iterative approach to reform allows policy makers to adjust and improvements throughout the policy cycle, rather than only after the final outcomes are received. In Chap. 4, for example, the authors discuss how the Taiwanese National Development Conference began designing the subsequent 12-Year reform, only two years into the 9-Year Reform, in response to early lessons from this reform and to incorporate emerging research from the global education movement. Similarly, in Chap. 3, we learn that Egypt's Ministry of Education and Technical Education adopted a phased approach to reform implementation, between 2018 and 2030. By describing and analyzing the implementation of this reform in its first two years, the authors offer a critical analysis that can inform the next phase of implementation.

Many of these chapters incorporate the voices and perspectives of the "street level bureaucrats" whose actions and decisions, in the face of intersecting opportunities, constraints, and daily routines "effectively become the public policies they carry out" (Lipsky, 1980). As detailed in the Methods section below, most chapters in this book include data from surveys, interviews or first-hand accounts from teachers, administrators and policy makers-key stakeholders that inform what policy looks like in practice. This reflects a "bottom-up" perspective (Lipsky, 1980) to understanding reform, suggesting that "in order to understand the success and failure of policy implementation, research has to consider policy as the outcome of implementation not as the input to the process" (Wegrich, 2016).

In addition, a study of reform that focuses exclusively on policy goals and outcomes has limited value for policy makers across diverse contexts, whose educational systems may present contextual differences from those of high performing countries. Focusing on the implementation of policy, instead, can give leaders the insight necessary to contextualize reforms. As Reimers (2021d, 7) notes:

\footnotetext{
Since countries are at various stages of educational development, in terms of their education priorities and institutional capacity, understanding how systems at various stages of educational development implement strategies to serve the learning needs of students can contribute to theorize what kind of strategies are appropriate at various stages. This can help understand how systems can build the capacity of teachers and administrators to pursue ambitious goals, and how such efforts at capacity building are supported by other institutional reforms.
}

The authors of each of these chapters place the specific reforms they study within their respective countries' historical and social national context. Taken together, these 
chapters provide a snapshot of the ways in which governments around the world are responding to a range of challenges, constraints, and opportunities to educate children for the twenty-first century, especially after the disruptions imposed by COVID-19.

In addition to showcasing implementation across a range of diverse contexts, this book also presents variation in the levels of policy analysis. Macro-level analyses examine reforms at the level of decisions and actions made by national actors and agencies in relationship to the influence of international agencies; meso-level analyses investigate the educational institutions in which learning occurs; and micro-level analyses explore individual actors within school systems such as teachers, parents, and students. While on the surface the chapters in these books reflect one of those levels, in practice they offer a multilevel analysis of reforms. For example, the chapters on Taiwan, Vietnam, Egypt, and Senegal are about macro country-level reforms; in comparison, the chapter examining the Multi-Skill Foundation Course (MSFC) is about regional, meso-levels of reform. Finally, the micro-level is explored in two chapters that focus on climate change-focused curriculum for an independent school in Washington, DC and Orange County schools.

Taken together, the way these reforms are evaluated connects macro, meso, and micro levels of analysis. First, many of the reforms are evaluated with both quantitative data as well as qualitative data regarding individual stakeholder's attitudes, motivation to learn, or confidence, which capture micro-level perspectives (Boeren, 2019). For example, the authors analyzing country-level reforms (such as Taiwan's 12-year basic education reform) or region-level reforms (such as the Multi-Skill Foundation Course in Maharashtra, India) integrate interviews and surveys with relevant stakeholders, such as local teachers, students, and school leaders. Conversely, the chapters on micro-level reform (those on climate change curriculum in Washington, DC and Orange County) utilize the five frames to examine these approaches to change from a macro-level perspective. For instance, in the chapter about climate change curriculum in Orange County, the authors recognize the challenges of teaching about climate change in a politically charged and controversial environment; they take these factors into account when creating their own regional curriculum. In addition, the chapter on Washington DC offers insight on how to scale a micro-level reform.

Multiple examples of reform and implementation analysis are used throughout this book, to provide a framework for connecting policy to practice and vice versa. These frameworks furthermore provide a closer view of the dynamics of reform, and what successful reform looks like in motion, so that teachers, schools' leaders, state leaders, and policy makers can work together to ensure successful implementation of policy goals at every level. 


\subsection{What Are Some of the Challenges in Producing This Kind of Real-Time Analysis?}

Although studying the implementation of educational reforms in diverse country contexts is important for the various reasons outlined above, this type of realtime analysis presents numerous challenges particularly when a comparative lens is applied. When analyzing educational reforms, we consider not only their inputs and outputs, but also their intended outcomes and broader societal impacts. Given this approach, perhaps the most significant challenge in conducting these real-time analyses lies in the difficulty of analyzing a reform that is still in progress. Given the evolutionary nature of reform, the process of analysis can be challenging. This is especially the case with bottom-up initiatives, such as those spearheaded by individual or groups of non-governmental organizations. In such bottom-up contexts the inputs and the strategies employed often vary across partner organizations and over time, as tactics evolve. A study in real time provides an incomplete picture of reforms, given their evolutionary nature; moreover, studying a reform in progress means clear outcome goals are not available during the time of the analysis. In some of the analyses, reforms are tracked as they transition from one operational strategy to another. For example, in India, the MSFC reform was studied as it transitioned from a school/local-based strategy in two schools-first in the LAHI model, and then to the scaled model in Maharashtra that operated in partnership with the state government. In this context, where the reform's operational strategy is in flux, analysis of the theory of action becomes clouded as the true nature of the strategy and full scale of the reform is not clear.

Another category of challenges with conducting real-time analysis for educational reforms lies in the analytical process itself-particularly with respect to access to, and study of, relevant data. None of the reforms are implemented in a vacuum. Even if reform strategies and goals remained consistent for the duration of the implementation, many of the reforms were implemented in contexts in which similar and or complementary programs were being executed—most likely impacting the outcome of the reform being analyzed.

In many cases, it is not immediately clear what data may be relevant for robust analysis of educational reform. In the MSFC chapter, for example, the authors note that the reform being studied - a twenty-first century-skill centered vocational course option for high schoolers-is often offered in schools where other students have other vocational-course options, which might result in similar outcomes although the authors are not able to analyze those alternatives. Similarly, in the Orange County climate change curriculum initiative, the authors are not able to account for the various other factors, both internal and external to the school system, which could influence students' environmental attitudes. In cases where it is clearer what data may be needed for analysis, such data is either insufficient or not immediately availableparticularly if the analysis is conducted in a relatively short timeframe. The analysis of the Egyptian reform exemplifies this limitation. Written documentation of the reform, 
financed and supported by a collaboration of private and public organizations, was limited and no formal articulation of the reform's strategy was available.

Despite the challenges of formulating a clear picture of the reform being analyzed or identifying and gaining access to the relevant data necessary to conduct a thorough study, it is still important and valuable to conduct such real-time analyses. As discussed earlier in the chapter such analyses provide a window into the messy process of implementation and highlight the numerous ways that reforms change over time depending on their provenance, their strategies, and other idiosyncratic factors unique to their diverse contexts.

\subsection{Competencies or Problems? Sequencing and Pacing of the Reform}

As the 2018 PISA report shows, in terms of global competencies, there exists considerable disconnect between knowledge and action among students; and, while what students are learning in schools about climate may be helping them understand the facts about climate change, it is not helping them discern what they can do about the challenge. Effective climate action curriculum is a pathway to close this gap. As evident in the case studies highlighted throughout this book, several reforms are moving towards building twenty-first century skills through competency-based curriculum. However, the two chapters on how climate change curriculum approach twenty-first century skills turn that approach on its head, by starting the design of curriculum with a focus on what problems the students should be prepared to solve, rather than focusing on which competencies they should gain.

This novel problem-based approach to the transformation of curricula is quite relevant to larger efforts to transform education, and more intentionally prepare students to address the many challenges augmented by the pandemic. Instead of focusing on developing specific skills such as collaboration, communication, creativity, and critical thinking, a problem-based curriculum is anchored globally-and then contextualized locally, so that students can learn, develop, and apply these 21 st-century skills within their relevant environments. The need to prepare students to address social challenges, and to contribute to building a better future, has augmented by the ripple-effects of COVID-19.

The two chapters presenting a novel climate change curriculum in this book differ from the remaining studies of reforms. Rather than offering a study of an ongoing or past reform, these two chapters are future-focused. They also differ in the proposed delivery and pacing of the reform strategy. Rather than a panoptic, system-wide reform, these studies rely on an incremental strategy, which begins with a pilot of a novel curriculum in one school, as a precondition to reform at scale. This contrast in approaches to reform is well grounded in the literature on reform. 
In examining the success record of reform at scale in the United States, Cohen and Mehta (2017) differentiate two types of reform and why they succeed: (1) systemlevel reforms that aim for wide-spread implementation, which succeed when they can work with existing levels of educational capacities and within widely-accepted culture, and (2) niche reforms, which are smaller-scale and often countercultural, and succeed when they mobilize champions to create a subsystem infrastructure to support the reform.

The authors of the two future-oriented chapters on climate change curriculum rely on a niche-, or micro-, level approach to reform. As the authors in the Orange County chapter explain, drawing on Cohen and Mehta's analysis of which reforms scale, the failure of national standards to integrate climate change suggests the opportunity for a niche-level reform-especially in the political context where climate change is not widely accepted, and where a large-scale reform would be unlikely to succeed.

In contrast, the authors of the chapter focusing on climate change curriculum in Washington, DC partnered with an independent school, which afforded them more curricular autonomy and with it, the opportunity to become an exemplar for other schools. Given the limitations of past curriculum reforms in educating for climate change, these chapters provide unique insight on the pacing of reform that transcends what has been attempted, instead of designing a novel approach to sequence and strategy.

By sequencing the reforms, these chapters propose a curricular reform that is not a complete pedagogical shift, but rather provides the opportunity to deepen curriculum that already exists. In addition, education reforms that scale tend to be "responsive to the unique demands and opportunities of national and local context" (Reimers, 2017). The authors emphasize the importance of integrating the local impacts of climate change to make a meaningful and relevant curricular reform within schools. Ultimately, these chapters allow us to explore how niche-level curricular reforms could be successful and how this consideration can be integrated in the development phase of reform. Our view is that these two perspectives on the approach to change, system level vs. niche, are complementary. Arguably, rather than determining whether niche-level reforms are more effective than system-wide reforms, it is more important to analyze when countries should implement a niche-level reform vs. a system-wide reform.

The first half of the book, which focuses on reforms that have already occurred or are in progress, also provides important (and different) insights into how to successfully pace and sequence of reforms. These chapters deal with several central questions: does the pacing of reform matter? Should reforms rely on pilots, staggered, or scale all at once? Each of the countries examined offers a different set of answers.

For example, in the case of Taiwan and Egypt, because of limited capabilities, both reforms used grade-level sequencing. In Egypt, the implementation ended up being accelerated by the pandemic, but the first phase of the reform covered K-2. This leads to a follow-up question: how should a sequenced reform be successfully implemented? In a recent OECD report, Schleicher (2018) analyzes how education reform successfully happens and that in particular, curricular reform is best done in a specific sequence, starting with pre-service or in-service teacher education. Instead 
of incremental grade level sequencing, should the first phase of reforms generally begin with teacher professional development and capacity building? Similarly, the reform in India started with 100 schools in Maharashtra with a focus of training their community members before transitioning into a larger scale initiative. Overall, this book gives an overview of different reforms that scale or attempt to scale in various ways to provide insights on the pacing and sequencing of reforms.

\subsection{Methods, Data and Limitations}

As students in the course on comparative education policy, the authors of these chapters studied a range of publications on system level reform. They were also provided a protocol to guide data collection. Because the study was conducted during the pandemic, during the period when there were physical distancing restrictions in place, most data were collected remotely, interviewing key informants via web conferencing or communicating via email. The evidence collected included records about the programs studied and individual or group interviews. No observations or face to face in person interviews were possible, given the restrictions in place during the pandemic.

The students in this course on education policy included educators with professional experience in Austria, Bangladesh, Belgium, Belize, Canada, China, Egypt, France, Germany, Greece, India, Italy, Japan, Kosovo, Palestine, Saudi Arabia, Senegal, Sierra Leone, South Africa, Spain, Taiwan, Thailand, Uganda, United Arab Emirates, United Kingdom, United States, Venezuela and Vietnam. Their professional roles included teacher, school leader, school principal, instructional coach, facilitator, trainer, curriculum designer, learning designer, consultant, director of international education, international development professional, fundraiser, and advocate-among other roles.

In the course, students were asked to study a reform of education that explicitly aimed at developing a breadth of skills. Students worked on these assignments in teams, choosing the specific focus and country for the study, in all cases at least one member of the team had direct access to relevant education authorities in the context studied, who could provide the information necessary to conduct the study. Four of the teams focused on education reforms underway or recent, and two of the teams focused instead on designing a curriculum reform which could address climate change. The students worked on these projects between the months of September and December of 2020, during the Covid-19 pandemic, as they were graduate students (online, due to COVID-19) at the Harvard Graduate School of Education. Upon completion of the research projects, the students presented them at a virtual conference, at which the projects received feedback from leaders of practice in the field of international development. Subsequently, students revised the chapters and presented them at a conference among all authors participating in this project, receiving feedback from peers and from the teaching team. 
While in each team at least one member had direct access to informants about the reforms they were studying, only one of the authors - the lead author of the study in Vietnam-works in a senior role in the government whose reforms are studied.

The studies rely on surveys, focus groups, published and unpublished documents, and interviews. No observations of classroom instruction or other activities carried out as part of these reforms were conducted.

The following data are included in the studies:

India: Surveys and focus groups of students, parents and community members; interviews of LAHI staff members; external impact assessments.

Taiwan: Literature review of scholarly articles, government documents, and official reports; stakeholder interviews with teachers, school administrators, and education researchers; and a survey administered to teachers.

Egypt: Literature review and interviews with teachers, administrators and policy makers. Access to a research project which is documenting the reform.

Vietnam: International reports and academic literature. Interviews with key stakeholders in Vietnamese education system. Primary sources from government. Senegal: Quantitative and qualitative data from literature review of academic papers, reports and articles, interviews with key stakeholders in the Senegalese government, international organizations (UN Ambassador), and education system (former teacher and former principal).

Orange County, USA: Literature review and interviews to identify barriers and challenges in climate change education to inform their proposed curricular reform. Washington DC, USA: Literature review and interviews with teachers, students, and students' caregivers to identify barriers and challenges in climate change education, as well as surveys with teachers who piloted part of their curriculum.

The nature of the data collected brings some inherent limitations to this research. The first is that the studies provide a retrospective account of these reforms, with data collected after the fact. It is therefore possible that the memories of informants about key events were influenced by the way the reform was implemented, or by its emerging results. Furthermore, no attempt was made to isolate the study of the reform implementation from other concurrent events, both inside and outside of the education system, which might have influenced the views of those interviewed. Because most of the data collected are based on documents and interviews, not observational, they are subject to various sources of bias that might influence reliability and validity of the reports.

Most of the evidence examined focuses on the components of the reform, its components and theory of action, and on implementation, with limited information on impact on teacher practice or student outcomes. The chapters which include information on teacher practices—such as Taiwan—or student skills—such as Indiadepend on self-reports, without information to establish a counterfactual. As a result, the studies are mostly about the implementation of these reforms, rather than studies of what those reforms achieved. 


\subsection{Summaries of the Chapters.}

\section{India}

This chapter explores the multi-skill foundations course (MSFC) collaboration between Lend-A-Hand India (LAHI), and the local government of Maharashtra, India. On a broader scale, the MSFC, a novel, multidisciplinary vocational course alternative for students in India's secondary schools, targets the increasing gap between the number of highly trained Indian workers needed in the job market and the corresponding number of highly skilled students produced by the school system. According to the chapter, this mismatch of supply and demand is due in part to the lack of practicality of traditional schooling, which is currently focused on memorization and oft-stigmatized vocational options, and overly-focused on trade skills, with little allowance of the importance of twenty-first century skills-skills which are directly correlated to students' long-term employability. In addition to addressing employability, LAHI's MSFC work aims to increase student retention and increase dignity of labor.

LAHI's MSFC model, which started as an independent community-focused initiative in 100 schools in Maharashtra, designed to train community members to deliver MSFC courses, eventually transitioned to a state-government sponsored model. In this model, the government provided financial and human resources support, and LAHI provided strategy, training, and other pedagogical support.

Through a mix of MSFC student surveys, focus groups with MSFC and non-MSFC students, parents and community members, the authors found that LAHI's programming was successful in increasing students' employability, engagement (including retention), and dignity of labor. They also found that the programming, through its strategy of using mix-gender groupings for its project-based activities, had a positive impact on community connections, gender relations, and gender roles. After the study, students reported positive cross-gender collaborative experiences, and parents reported male students participating in domestic chores.

The chapter concludes with observations of the study's limitations, and suggestions regarding ways to improve the quality of the programming experiences, the connection between the programs and community, and the number of students and communities impacted. A model of the program's chief attributes is also presented and proposed as an exemplar to be copied in other contexts.

\section{Egypt}

This chapter examines an ambitious reform to improve the quality of education in Egypt. The reform intended to develop a breadth of competencies, following a life skills framework developed by UNICEF, and to support students in developing them through an interdisciplinary curriculum enabled by technology. The implementation of the reform depended on short professional development courses offered to teachers. The reform was financed and supported by a range of international organizations, including inter-governmental agencies such as UNICEF, the World Bank, and USAID, as well as an international education company. The chapter describes 
that written documentation about the reform is absent, and that no formal and public articulation of the reform's theory of action or logic framework exists. The COVID19 pandemic accelerated the implementation of some components of the reform, particularly the reliance on distance learning.

The chapter similarly examines the reform through the five perspectives framework, concluding that the reform lacks explicit consideration of cultural, professional and political perspectives, relying instead on psychological and institutional perspectives.

\section{Taiwan}

Taiwan's education reform extended the duration of compulsory education to twelve years, while also using the curriculum as an instrument to help students develop breadth of skills, or 21 st-century century skills, building on a previous competencybased curriculum reform, that had similarly emphasized educating the whole child up until the ninth grade. The new curriculum aspired to comprehensive preparation for work, life, and civic engagement, emphasizing the importance of educating for lifelong learning. The implementation theory of this reform addressed curriculum, teacher practice, assessment, instructional resources, professional development, administration, parent participation, and partnerships with nongovernmental organizations. It further emphasized achieving coherence and alignment across these various components of the reform.

This chapter also analyzes the implementation of the reform using the five perspectives of educational change studied in the course and discussed above. While the reform was found to be successful in expanding access and in implementing the new competency-based curriculum there were nonetheless some implementation challenges. These include insufficient teacher involvement in the curriculum review and design, the perception that the reform increased the burdens on teachers' time, insufficient public understanding of the reform's goals, and resistances to shifting cultural mindsets about schooling and its purposes.

\section{Vietnam}

This chapter presents an analysis of Resolution 29, passed in 2013, which aimed to fundamentally reform Vietnam's educational system from pre-school through higher education. This reform proposed eight key solutions, across education management and administration, teacher professional development, content and pedagogy, assessment, and resources. Resolution 29 also includes specific mandates to strengthen connections between universities and the labor market, foster education for disadvantaged groups, and improve international cooperation in the education sector.

The authors use the five perspectives framework to analyze the reform, and present data from the first seven years of the reform's implementation. Authors highlight key successes from this reform, including the approval of a new competency-based curriculum, and significant changes to high school graduation and university entrance examinations. Moving beyond Resolution 29, the authors recommend focusing on providing high quality training for teachers, especially around pedagogical methods, 
developing assessments to emphasize project-based learning in place of rote memorization, and building stronger systems for the management of education at all levels.

\section{Senegal}

This chapter focuses on the Cases des Tout-Petits (CTP) — an early education program launched in 2006, with the goal of building 28,000 community- based spaces to provide learning and health services for rural children from birth to 6 years of age. These services included health screening for deficiencies and disorders, immunization, offering children nutritious meals, and providing early childhood educational activities in literacy, math, technology, and cultural and moral values. Parents and community members were integrated into programming, to support whole child development. Community funding was also integrated into the model, to ensure local investment and reduce overreliance on governmental support. This reform is highlighted because of its unique integration of education and health, which may demonstrate important implications for future reforms that aim to consider the relationship between these two critical fields.

The authors use the five perspectives framework to analyze the implementation of this reform and identify gaps in the theory of action that may have affected its impact. Key challenges include need for appropriate staffing and training to support the program's dual purposes, a more robust financial model to support sustainability, lack of student achievement data, insufficient coordination among all stakeholders, and a high student-teacher ratio. Authors conclude that the reform demonstrates mixed results, and argue for a clear focus on teacher professionalization, monitoring and evaluation, and systemic coordination, in subsequent education policy.

\section{Orange county, USA}

This chapter analyzes the failure of standards (the Next Generation Science Standards) to translating a relevant and crucial global challenge, climate change, into classrooms in Orange County, California - as the authors argue, this is due largely to the decentralized education system in the US, the politicization of climate change, and lack of adequate professional development and resources for educators. The authors conducted interviews with teachers in Orange County and analyzed best practices in countries successful in wide-scale climate change education (Italy and Sweden), with the goal of offering a curriculum for education leaders to understand best practices of climate change education, and then implement these practices within their own local contexts.

The curriculum's theory of change is that if schools had an action-oriented and accessible curriculum, which fostered a sense of common purpose with peer-to-peer learning, then we would see students adopt more environmentally conscious behaviors-such as choosing biking over driving. These behaviors could then influence behaviors in the wider community. This curriculum is therefore peer-led and actionbased, with the following modules: "It's real," "It's us," It's bad," and "There's hope." In addition, the curriculum makes the topic personally relevant, transdisciplinary, 
and solution-oriented with explicit content on systems thinking and addressing the controversy behind climate change.

\section{Washington DC, USA}

This chapter analyzes existing climate change education curriculum worldwide, to form a program and implementation plan for an elementary climate-change focused curriculum at the school level. The authors partnered with an independent school in Washington, DC, with two major objectives: first, building a relevant curriculum, and second, modeling how a niche school-level curricular reform could then be translated to a systemic level reform. Their curriculum's theory of change is if students understand the science of climate change, recognize its impacts on their local communities, and create community-oriented solutions leveraging four sectors (media, government, corporate sector, and individual engagement), then they will also be able to apply their learning into actions to address climate change issues. Ultimately, the goal of this curriculum is to create collaborative leaders with twenty-first century skills, who are enabled to prioritize climate action.

The principles behind the curriculum are community-based, participatory, and interdisciplinary learning. In addition, the authors outline a logical framework that emphasizes the importance of building a relationship with school administrators and teachers for feedback and buy-in, forming a core group of champion teachers, providing professional development opportunities for teachers, and adapting the piloted curriculum to other existing programs in the school.

\section{References}

Boeren, E. (2019). Understanding Sustainable Development Goal (SDG) 4 on "qualityeducation" from micro, meso and macro perspectives. International Review of Education, 65(2), 277-294. https://doi.org/10.1007/s11159-019-09772-7

Cohen, D. K., \& Mehta, J. D. (2017). Why reform sometimes succeeds: Understanding the conditions that produce reforms that last. American Educational Research Journal, 54(4), 644-690. https://doi.org/10.3102/0002831217700078

Dalin, P., \& Ayono, T. (1994). How schools improve: An international report (School development series). Cassell.

Donnelly, R., \& Patrinos, H. (2021). Learning loss during COVID-19: An early systematic review. Covid Economics, 77, 145-153.

Global Partnership for Education. (2020). 21st Century skills: What potential role for the global partnership for education. A landscape review. https://www.globalpartnership.org/content/21stcentury-skills-what-potential-role-global-partnership-education. Accessed 14 June 2021.

Hargrove, E. (1975). The missing link: The study of the implementation of social policy (An Urban Institute paper; 797-1). Urban Institute.

Lee, S. K., Lee, W. O., \& Low, E. L. (2014). Educational policy innovations. Springer.

Lipsky, M. (1980). Street level bureaucracy. Russell Sage Foundation.

Majone, G., \& Wildavsky, A. (1979). Implementation as evolution (pp. 163-180).; Pressman, J., \& Wildavsky, A. (1984). Implementation (3rd edn) (original edition 1975). University of California Press. 
OECD's Future of Education and Skills 2030 Initiative. https://www.oecd.org/education/2030-pro ject/. Accessed 14 June 2021.

Pressman, J. L., \& Wildavsky, A. B. Implementation.; In Balla, S. J., Lodge, M., \& Page, E. C. (2015). The Oxford handbook of classics in public policy and administration (Oxford handbooks). Oxford University Press, USA, OSO.

Reimers, F. (2017). Empowering all students at scale. Createspace.

Reimers, F. (Ed.). (2020a). Audacious education purposes. Springer.

Reimers, F. (Ed.). (2020b). Educating students to improve the world. Springer.

Reimers, F. (2021a). Education and COVID-19: Recovering from the shock created by the pandemic and building back better. Geneva, Switzerland: UNESCO. International Bureau of Education and International Academy for Education. Educational Practices Series 34.

Reimers, F. (Ed.). (2021b). Education and climate change. Springer.

Reimers, F. (Ed.). (2021c). Implementing deeper learning. Springer.

Reimers, F. M. (2021d). In search of a twenty-first century education renaissance after a global pandemic. In: F. M. Reimers (eds.), Implementing deeper learning and 21 st century education reforms. Springer. https://doi.org/10.1007/978-3-030-57039-2_1.

Reimers, F. (Ed.). (2022). Primary and secondary education during COVID-19. Springer.

Schleicher, A. (2018). Making education reform happen (pp. 203-225). https://doi.org/10.1787/ 9789264300002-5-en.

Schleicher, A. (2019). PISA 2018. Insights and Interpretations. Paris: OECD. https://www.oecd. org/pisa/PISA\%202018\%20Insights\%20and\%20Interpretations\%20FINAL\%20PDF.pdf.

UNESCO. (2021). Commission on the futures of education. https://en.unesco.org/futuresofeducat ion/. Accessed 14 June 2021.

Wang, Y. (Ed.). (2013). Education policy reform trends in G20 members. Springer.

Wegrich, K. (2016). Jeffrey L. Pressman and Aaron B. Wildavsky, Implementation.; In Balla, S. J., Lodge, M., \& Page, E. C. (2015). The Oxford handbook of classics in public policy and administration (Oxford handbooks). Oxford University Press, USA, OSO.

World Bank. (2018). World development report. Learning to realize education's promise. Washington, DC: International Bank for Reconstruction and Development/The World Bank.

Fernando M. Reimers is the Ford Foundation Professor of the Practice of International Education and Director of the Global Education Innovation Initiative and of the International Education Policy Master's Program at Harvard University. An expert in the field of Global Education, his research and teaching focus on understanding how to educate children and youth so they can thrive in the 21st century. He is a member of UNESCO's high-level commission on the Futures of Education.

Uche Amaechi is a Lecturer on Education at the Harvard Graduate School of Education where he teaches about leadership, organizational behavior, and social entrepreneurship. Uche is also the ELT coordinator at the Fletcher Maynard Academy where he works on school leadership, community engagement, and matters of race and equity. Uche also sits on the boards of schools and nonprofit organizations focused on supporting students from underrepresented groups.

Alysha Banerji is a Ph.D. student at the Harvard Graduate School of Education and an Editor at the Harvard Educational Review. Her research focuses on the ethics of citizenship and civic education for global citizenship. She has an M.S. Ed in International Education Development from the University of Pennsylvania and has experience working in education in India, the USA, and Chile. 
Margaret Wang is an M. Ed in International Education Policy graduate of Harvard Graduate School of Education. Previously a high school economics and social studies teacher in Bahrain, she is now committed to helping the youth be stewards of the sustainable development goals. She is currently the co-founder of Subject To Climate, an online connector for K-12 educators to find climate change teaching resources, and innovate for Africa, a social impact organization supporting aspiring African entrepreneurs.

Open Access This chapter is licensed under the terms of the Creative Commons Attribution 4.0 International License (http://creativecommons.org/licenses/by/4.0/), which permits use, sharing, adaptation, distribution and reproduction in any medium or format, as long as you give appropriate credit to the original author(s) and the source, provide a link to the Creative Commons license and indicate if changes were made.

The images or other third party material in this chapter are included in the chapter's Creative Commons license, unless indicated otherwise in a credit line to the material. If material is not included in the chapter's Creative Commons license and your intended use is not permitted by statutory regulation or exceeds the permitted use, you will need to obtain permission directly from the copyright holder.

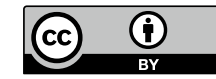

